through a deep trough, or hollow of a wave, in the surface of the atmospheric ocean ; in which the diminution of the friction might occasion a loss of incandescence; a suggestion rather favoured by the repetition of the phenomenon. Perhaps the meteor was only making ducks and drakes.

Rainhill, November i7

HENRY H. Higgins

\section{Integrating Anemometer}

J'AI lu avec beaucoup d'intérêt la controverse suscitée dans les colonnes de votre estimable journal, à propos de "l'Anémomètre Intégrateur" présenté par M. Hele Shaw et le Dr. Wilson à la dernière réunion de "l'Association Britannique." Il arrive souvent, dans l'histoire des inventions, qu'une même idée, quoique diversement modifiée, vient presque simultanément à l'esprit de plusieurs individus travaillant dans des direction indépendentes, et il en résulte ainsi des questions de priorite difficiles à décider.

Ce n'est pas pour une question de ce genre que j'ose vous écrire anjourd'hui; mais l'idée de l'anémomètre intégrateur m'était venue aussi il y a quelques années, et la description de celui inventé par M. A. von Oettingen, que j'ai lu dans le "Repertorium "de M. Wild en juillet, 1878 , me conduisit, si je n'ai pas mal compris, à la forme même de l'appareil de MM. Shaw et Wilson, et quelques jours plus tard à une autre, plus parfaite à mon avis, et que je n'ai pas encore eu l'occasion de mettre en pratique. C'est celle dont les organes les plus essentiels ont éte représentés dans les figures ci-jointes.

Un disque (roller) vertical A peut, comme dans l'instrument de MM. Shaw et Wilson, prendre la même orientation que la girouette et au même temps tourner sur son axe horizontal avec une vitesse proportionelle a celle du vent. Sur ce disque s'appuit une sphère $B$, de poids et dimensions convenables, qui est aussi soutenu lateralement par quatre disques verticaux N., E. S., W., situés à angle droit entre eux. Le disque $\mathrm{A}$ fait mou. voir la sphère $\mathrm{B}$ dans le même plan vertical, et celle-ci les quatre disques lateraux; de sorte que, si les points de contact de ces disques avec la sphère ont lieu sur l'équateur dont le pôle est le point de contact du disque moteur, la vîtesse totale de celui-ci s'y trouvera decomposée dans les directions fondamentales $\mathrm{N}$., S., E., W. Dès lors il suffira de munir chaque disque N., E.,

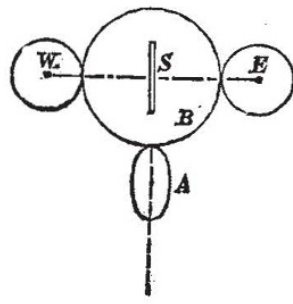

Projection verticale.

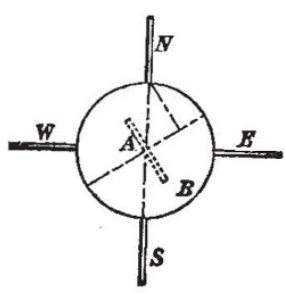

Projection horizontale.
S., W., ou bien deux disques quelconques adjacents, d'un compteur spécial, pour obtenir les composantes cardinales du vent.

Cet anémomètre intégrateur sera, comme ceux de MM. Shaw et Wilson et de M. Lurton, plus simple que celui de M, von Oettingen, et en outre son action deviendra, pour ainsi dire, indéfinie, la transmission du mouvement s'y effectuant au moyen d'une sphère. Cette transmission se fait ici par roulement sans glissement, ce qui n'a pas lieu dans le système de M. von Oettingen, où cette circonstance constitue un grave défaut.

Pour ne pas prolonger trop cette lettre, je n'insisterai plus sur mon anémomètre, dont les indications peuvent être obtenues de diverses manières, et dont le mécanisme est susceptible de recer. voir plusieurs applications.

$\mathrm{Si}$ vous croyez que les lignes précédentes contiennent quelqu'idée nouvelle et utile, je vous prie de vouloir bien les insérer dans votre estimable journal. En attendant je vous remercie d'avance, et veuillez aussi, Monsieur, agréer l'assurance de ma plus haute estimation.

Madrid, le 5 novembre

V. VENTOSA

\section{Geological Results of the Late Gales}

THE late gales have had a very powerful effect in redistributing the beach-deposits along our coasts, and though many well-known geological sections have no doubt been covered up in consequence, many new ones have at the same time been brought to light. In this neighbourhood, for instance, a Whitley-by-the-Sea, near Tynemouth, a section of the highest interest to local geologists has been uncovered within the last few weeks, showing a well-marked uncomformity within the Coal-measures, which I, for one, although familiar with the place for years, was totally unaware of, and which, if ever observed before, has certainly never been recorded. For some time to come the section will probably remain exposed at low tides, as the sand which formerly concealed it has been entirely swept away. I will not weary your readers with a detailed description of the section, which will, in due time, be more appropriately published elsewhere, but merely beg to record the observation as an example of the kind of new matter that many geologists resident on or near our coasts will probably come across by searching along the cliff-bases just now. G. A. LEBOUR

November 15

\section{The Recent Weather}

AT II o'clock last night two thermometers outside stood at $66^{\circ} \cdot 75$. It was pitch dark, and blowing fresh from south-south. west. When last tested, these thermometers were not 25 of a degree in error. Was such a temperature ever registered at such an hour on the $13^{\text {th }}$ November before in Great Britain or Ireland?

Bray, Co. Wicklow, Ireland, November I4

\section{Dipladenia amabilis}

Ir it is not already well known, it may intere st some of your readers to hear that flowers of the Dipladcria amabilis last for a much longer time when placed in water if their tubes be also filled. Even when "too utterly weary" they can be revived in the manner I have mentioned. This may have reference to the fact that these flowers, unlike many creepers, generally turn upwards, and would therefore be likely to catch rainwater.

$$
\text { High Elms, Hayes, Kent, November I } 3
$$

Amy Mulholland

\section{"The Lepidoptera of Ceylon"}

Wirh reference to the remarks of Dr. H. Trimen (vol, xxy, p. 32) to this work, now in course of publication under the patronage of the Ceylon Government, of which Parts I. and II. only had then reached him, and especially to the "protest" which he "feels bound to enter" against the name of the artist as there printed at the foot of the several plates, I may be allowed to state that the original drawings made by the native artist, Mr. W. de Alwis (representing about 350 species, or onethird only of the number of Ceylon Lepidoptera known to the author, and that will eventually be figured in this work), which Dr. Trimen states are in the Colombo Museum, were copied by his brother, Mr. George de Alwis, for Sir William H. Gregory, whilst Governor of the Island. These copies are in the author's hands, and it is from them, wherever a suitable figure is available, as well as from specimens of the actual species there represented, that the drawings, and afterwards the lithographing the figures on the stone, were made. The artist's name, as there printed on the several plates of the work, is consequently perfectly correct. In due course, Part IV.- completing vol. i. of this work-will reach Ceylon, wherein the preface is printed, and Dr. Trimen will there see that the native artist to whom he so specially refers, receives the necessary acknowledgment of his labours from the author.

Penge, S.E.

F. MOORE

A GLIMPSE THROUGH THE CORRIDORS OF $T I M E^{1}$

I.

YOUR Committee has done me much honour by inviting me to deliver the first lecture in this large and very beautiful hall. In accepting the task I was aware that it involved a great responsibility, but I had various grounds of encouragement. I remembered that I was not coming among you as a stranger, and I knew that I had a subject worthy of a memorable occasion. I would I were

I Lecture delivered at the Midland Institute, Birmingham, on October 24, 1881, by Prof. Robert S. Ball, LL.D., F.R. S., Andrews Professor of Astronomy in the University of Dublin, and Royal Astronomer of Ireland. 
equally confident of my ability to do justice to so noble a theme.

The lecture bears the somewhat poetic title of "A Glimpse through the Corridors of Time." A poetic title has been chosen, because if I can properly exhibit the subject you will see that it appeals powerfully to the imagination as well as to the reason. I shall invite you to use your imagination to aid in looking back into the very remotest recesses of antiquity. And when I speak of antiquity I do not mean the paltry centuries with which our historians have to deal. The ancient days to which I refer are vastly anterior to those of the "grand old masters" and those of the "bards sublime." Nor do we even allude to the thousands of years which have elapsed since Babylon and Nineveh were splendid and populous cities Even the noble pyramids of Egypt are but of yesterday when compared with the æons of years which must pass before our review.

The most ancient human monuments that now exist cannot, I suppose, be more than a few thousand years old. Five thousand years nearly exhausts all historical time. Ten thousand years certainly does. Though we have no earlier historical record, yet other records are not wanting. Geology tells us that ten thousand years is but a mere moment in the span of the earth's history. We learn from geology that even the career of man himself has lasted far more than ten thousand years. Yet man is but the latest addition to the succession of life on the earth. For the chronology of the earlier epochs of the earth's history we require majestic units to give adequate expression to our dates. Thousands of years are not sufficient, nor tens of thousands, nor hundreds of thousands. The course of geological time is to be reckoned in millions of years.

The corridors of time through which I wish to give you a glimpse are these dignified millions. Yet our retrospect will only extend to a certain definite epoch in the past history of our earth. We speak of nothing anterior to the time when our earth assumed the dignity of maternity, and brought forth its first and only child. We shall trace the development of that child which, though millions of years old, is still in dependence on its parent. We shall describe the influence of the parent over the child and the not less remarkable reaction of the child upon the parent. We shall foreshadow the destiny which still awaits the mother and child when millions of years shall have elapsed.

At the time of its birth the earth was not as we see it now, clothed with vegetation and teeming with animal life. It was a huge inorganic mass, too hot for life, perhaps hot enough to be soft or viscid, if not actually molten. The offspring was what might be expected from such a parent. It was also a rude inorganic mass. Time has wrought wondrous changes in both parent and child. Time has transformed the earth into an abode of organic tife. It has transformed the earth's offspring into our silvery moon.

It will be my duty to sketch for you the manner in which these changes have been brought about. To a great extent we can do this with no hesitating steps, we are guided by a light which cannot deceive. It is the light of mathematical reasoning. These discoveries are of an astronomical character, but they bave not been made by telescopes. They have been made by diligent labours of the most abstruse kind. The mathematical astronomer sits at his desk, and not in an observatory. He has in his hand a pen and not a telescope. Before him lies a sheet of paper and not the starry heavens. $\mathrm{He}$ is no doubt furnished with a few facts from observation. It is his province to interpret those facts, to inform them with life, and to infer the unknown from the known. It is thus discoveries are made which are the sublimest efforts of human genius.

The argument on which I invite you to follow me is founded on a very simple matter. Many of those present go every summer to the sea-side. Those who do so are well acquainted with the daily ebb and flow which we call the tides. Even the children with their spades and buckets know how the flowing tide will fill their moats lug in the sand and inundate their mimic castles. In the ebb and flow of the tide we have a mechanical engine of mighty power. I hope this evening to point out the wonderful effect which tides have had on the earth in times past, as well as the effect they will exercise in the future. It is the tides which are to reveal to us a glimpse through the Corridors of Time.

The cause of the ebb and flow of the tide has long ceased to be a mystery. In the earliest times it was noticed that the tides were connected with the moon. Pliny and Aristotle both refer to the alliance between the tides and the age of the moon. It is well known that the tides on our coasts sometimes rise to an unusual height. Those who dwell on low ground adjoining tidal rivers are painfully aware of this fact by the floods which are often produced. Such occurrences generally take place at the time of new moon or of full moon. At first quarter or last quarter the tides are even below the usual height. A fisherman who has to regulate his movements by the tides will know full well that at certain times the tides rise higher and fall lower than at other times. He brings his boat out on the falling tide, he brings it back on the rising tide, and when making the harbour after a night's fishing, it would be natural to hear him say "Oh, we shall run in easily this morning, there is a strong tide, the moon was full last night." Or if he had to cross a dangerous bank he would soon learn the difference between the spring tide and the neap. Fishermen are not much addicted to abstract reasoning. For many centuries, perhaps indeed for thousands of years, observant men might have known that the moon and the tides were connected. But they did not know any reason why this connection should exist. I daresay they did not even know whether the moon was the cause of the tides or the tides the cause of the moon.

Nor is it easy to explain the tides. We were all taught that the moon makes the tides. Yet I can imagine an objector to say, If the moon makes the tides, why does it give Bristol a splendid tide of 40 feet, while London is put off with only 18 ? The true answer is that the height of the tide is largely affected by local circumstances, by the outline of the coasts, by estuaries and channels. It is even affected to some extent by the wind. Into such details, however, I do not now enter : all I require is that you shall admit that the moon causes the tides, and that the tides cause currents. In some few places the currents caused by the tides are made to do useful work. A large reservoir is filled by the rising tide, and as the water enters it turns a water-wheel. On the ebbing tide the water flows out of the reservoir, and again gives motion to a water-wheel. There is here a source of power, but it is only in very exceptional circumstances that such a contrivance can be worked economically. Sir W. Thomson, in his address to Section A of the British Association at York, went into this question in its commercial aspect. At present, however, we may say that the power of the tides is as much wasted as is the power of Niagara. Perhaps when coal becomes more scarce, and when the means of distributing power by electricity are more developed, the tides and the great waterfalls will be utiiised; but that day will not be reached while coal is only a few shillings a ton.

Though we have not yet put the tides into harness, yet tides are not idle. Work they will do, whether useful or not. In some places the tidal currents are scouring out river-channels; in others they are moving sandbanks. From a scientific point of view the work done by the tides is of unspeakable importance. To realise the importance, let us ask the question, Whence is this energy 
derived with which the tides do their work? The answer seems a very obvious one. If the tides are caused by the moon, the energy they possess must also be derived from the moon. This looks plain enougb, but unfortunately it is not true. Would it be true to assert that the finger of the rifleman which pulls the trigger supplies the energy with which the rifle bullet is animated? Of course it would not. The energy is derived from the explosion of the gunpowder, and the pulling of the trigger is merely the means by which that energy is liberated. In a somewhat similar manner the tidal wave produced by the moon is the means whereby a part of the energy stored in the earth is compelled to expend itself in work. I do not say this is an obvious result. Indeed it depends upon a refined dyriamical theorem, which it would be impossible to enter into here.

But what do we mean by taking energy from the earth? Let me illustrate this by a comparison between the earth rotating on its axis and the fly-wheel of an engine. 'The Aly-wheel is a sort of reservoir, into which the engine pours its power at each stroke of the piston. The various machines in the mill merely draw off the powcr from the store accumulated in the fly-wheel. The earth is like a gigantic fly-wheel detached from the engine, though still connected with the machines in the mill. In that mighty fly-wheel a stupendous quantity of energy is stored up, and a stupendous quantity of energy would be given out before that fly-wheel would come to rest. The earth's rotation is the reservoir from whence the tides draw the energy they require for doing work. Hence it is that though the tides are caused by the moon, yet whenever they require energy they draw on the supply ready to hand in the rotation of the earth.

The earth differs from the fly-wheel of the engine in a very important point. As the energy is withdrainn from the fly-wheel by the machines in the mill, so it is restored thereto by the power of the steam-engine, and the fly runs uniformly. But the earth is merely the fly-wheel without the engine. When the work done by the tides withdraws energy from the eartb, that energy is never restored. It therefore follows that the energy of the earth's rotation must be decreasing, This leads to a consequence of the most wonderful importance. It tells us that the speed with which the earth rotates on its axis is diminishing. We can state the result in a manner which has the merits of simplicity and brevity.

"The tides are increasing the length of the day."

This statement is the text of the discourse which I am to give you this evening. From this simple fact the new and wondrous theory of tidal evolution is deduced. A great scientific theory is gencrally the outcome of many minds. To a certain extent this is true of the theory of tidal evolution. It was Prof. Helmholtz who first appealed to what tides bad already done on the moon. It was Prof. Purser who took an important step in the analytical theory. It was Sir William 'Thomson's mathematical genius which laid the broad and deep foundations of the fabric. These are the pioncers in this splendid research. But they were only the pioneers. The great theory itself is chiefly the work of one man. You are all familiar with the name he bears. The discoverer of tidal evolution is Mr. G. H. Darwin, Fellow of Trinity College, Cambridge.

It would be impracticable for me now to go into the actual mathematical calculations. I shall rather endeavour to give you an outline of this theory, shorn of its technical symbols. I think this can be done even though we attempt to retain the accuracy of mathematical language. Nor would it be fair to throw on $\mathrm{Mr}$. Darwin or the other mathematicians I have named the responsibility for all I am going to say. I must be $m y$ self responsible for the way in which those theories are set fortn, as well as for some of the deductions made from them.
At present no doubt the effect of the tides in changing the length of the day is very small. A day now is not appreciably longer than a day a hundred years ago. Even in a thousand years the change in the length of the day is only a fraction of a second. But the importance arises from the fact that the change, slow though it is, lies always in one direction. The day is continually increasing. In millions of years the accumulated effect becomes not only appreciable but even of startling magnitude.

The change in the length of the day must involve a corresponding change in the motion of the moon. This is by no means obvious. It depends upon an elaborate mathematical theorem. I cannot attempt to prove this for you, but I think I can state the result so that it can be understood without the proof. If the moon acts on the earth and retards the rotation of the earth, so, conversely, does the carth react upon the moon. The earth is tormented by the moon, so it strives to drive away its persecutor. At present the moon revolves round the earth at a distance of about 240,000 miles. The reaction of the earth tends to increase that distance, and to force the moon to revolve in an orbit which is continually getting larger and larger.

Here then we have two remarkable consequences of the tides which are inseparably connected. Remember also that we are not enunciating any mere speculative doctrine. These results are the inevitable consequence of the tides. If the earth had no seas or oceans, no lakes or rivers ; if it were an absolutely rigid solid throughout its entire mass ; then these changes could not take place. The length of the day would never alter, and the distance of the moon would only fluctuate between narrow limits.

As thousands of years roll on, the length of the day increases second by second, and the distance of the moon increases mile by nile. These changes are never reversed. It is the old story of the perpetual dropping. As the perpetual dropping wears away the stone, so the perpetual action of the tides has sculptured out the earth and moon. Still the action of the tides continues. To-day is longer than yesterday; yesterday is longer than the day before. A million years ago the day probably contained some minutes less than our present day of twenty-four hours. Our retrospect does not halt here; we at once project our view back to an incredibly remote epoch which was a crisis in the history of our system.

Let me say at once that there is great uncertainty about the date of that crisis. It must have been at least $50,000,000$ years ago. It may have been very much carlier. This crisis was the interesting occasion when the moon was born. I wish I could chronicle the event with perfect accuracy, but I cannot be sure of anything except that it was more than $50,000,000$ years ago.

I do not admit that there is anything discreditable about this uncertainty. Do you not know that our historians, who have records and monuments to help them, are ofter in great confusion about dates? I am not going to find any fault with historians. They do their best to learn the truth; but I cannot help reminding you that they are often as nuch in the dark about centuries as the astronomers are about millions. Take, for example, the siege of Troy, which Homer has immortalised, and ask the historians to state the date of that event. Some say that the siege of Troy was 11 84 B.C., others that it was 900 B.C.; both are equally uncertain. Schliemann say's that he found the remains of the town burned down, but that no one knows who did it or when it was done. Others, again, say that there was never any siege of Troy at all.

A recent instance which has attracted great and deserved attention is Schliemann's discovery at Mycenie of what he considers to have been the tomb of Agamemnon. The tomb certainly did contain the remains of some mighty man, if we may jutge by the $100 \mathrm{lb}$. weight of 
gold ornaments which were found there. Most people think that these tombs, whosever they were, date from at least 1000 B.C. On the other hand, some very high authorities regard the monuments as the tombs of northern invaders who came into Greece 500-600 A.D. Here then we have a range of some 1500 years for the date of the tombs, and no dates between these two are possible. I am sure I do not pretend to decide between them, or even to have an opinion on the subject; but I cannot help saying that in one respect the astronomers are better off than the historians. The historians cannot even agree whether Schliemann's gold ornaments are B.C. or A.D. Astronomers are, at all events, certain that the date of the moon's birth was before the present era.

At the critical epoch to which our retrospect extends, the length of the day was only a very few hours. I cannot tell you exactly how many hours. It seems, however, to have been more than two and less than four. If we call it three hours we shall not be far from the truth. Perhaps you may think that if we looked back to a still earlier epoch, the day would become still less and finally disappear altogether! This is however not the case. The day can never have been much less than three hours in the present order of things. Everybody knows that the earth is not a sphere, but that there is a protuberance at the equator, so that, as our school books tell us, the earth is shaped like an orange. It is well known that this protuberance is due to the rotation of the earth on its axis, by which the equatorial parts bulge out by centrifugal force. The quicker the earth rotates the greater is the protuberance. If, however, the rate of rotation exceeds a certain limit the equatorial portions of the earth could no longer cling together. The attraction which unites them would be overcome by centrifugal force, and a general break up would occur. It can be shown that the rotation of the earth when on the point of rupture corresponds to a length of the day somewhere about the critical value of three hours, which we have already adopted. It is therefore impossible for us to suppose a day much shorter than three hours. What occurred prior to this I do not here discuss.

Let us leave the earth for a few minuics, and examine the past history of the moon. We have seen the moon revolves around the earth in an ever-widening orbit, and consequently the moon must in ancient times have been nearer the earth than it is now. No doubt the change is slow. There is not much difference between the orbit of the moon a thousand years ago and the orbit in which the moon is now moving.

But when we rise to millions of years the difference becomes very appreciable. Thirty or forty millions of years ago the moon was much closer to the earth than it is at present; very possibly the moon was then only half its present distance. We must however look still earlier, to a certain epoch not less than fifty millions of years ago. At that epoch the moon must have been so close to the earth that the two bodies were almost touching. I daresay this suriking result will come upon many with surprise when they hear it for the first time. It was, I know, with great surprise that I myself read of it not many months ago. But the evidence is unimpeachable, and it is indeed wonderful to see how such information has been gained by merely looking at the ripples of the tide.

Everybody knows that the moon revolves now around the earth in a period of twenty-seven days. The period depends upon the distance between the earth and the moon. The time and the distance are connected together by one of Kepler's celebrated laws, so that, as the distance shortens, so must the time of revolution shorten. In earlier times the month must have been shorter than our present month. Some millions of years ago the moon completed its journey in a week instead of taking twenty-eight days as at present. Looking back earlier still, we find the month has dwindled down to a day, then down to a few hours, until at that wondrous epoch when the moon was almost touching the earth, the moon spun round the earth once every three hours.

It would require the combined powers of a poet and a mathematician to pourtray the scene with becoming dig. nity. I have only promised to give you that glimpse along the Corridors of Time which I have myself been able to obtain. The scene is laid in the abyss of space; the time is more than $50,000,000$ years ago ; the dramatis personce are the earth and the moon.

In those ancient times I see our earth to be a noble globe, as it is at present. Yet it is not partly covered with oceans and partly clothed with verdure. The primæval earth seems rather a fiery and half-molten mass, where no organic life can dwell. Instead of the atmosphere which we now have, I see a dense mass of vapours in which perhaps all the oceans of the earth are suspended as clouds. I see that the sun still rises and sets to give the succession of day and of night, but the day and the night together only amount to three hours instead of twenty-four. Almost touching the chaotic mass of the earth is another much smaller and equally chaotic body. Around the earth I see this small body rapidly rotating. The two revolve together as if they were bound by invisible bands. This smaller body is the moon. Such is the picture which I wish to present to you as a glimpse through the Corridors of Time.

I have hitherto refrained from introducing any merely speculative matters. If we can believe anything of mathematics, anything of dynamics, we must admit that the picture I have attempted to outline is a faithful portrait. The only uncertain elements are the date and the periodic time. I do however now propose to venture on one speculation in which Mr. Darwin has indulged. I propose to offer a suggestion as to how a small body came into this most remarkable position close by the earth, and how its motion was produced.

We have hitherto been guided by the unerring light of dynamics, but at this momentous epoch dynamics deserts us, and we have only probability to guide our faltering steps. One hint, however, dynamics does give. It reminds us that a rotation once in three hours is very close to the quickest rotation which the earth could have without falling to pieces. As the earth was thus predisposed to rupture, it is of extreme interest to observe that a cause tending to precipitate such a rupture was then ready to hand. It seems not unlikely that we are indebted to the sun as the occasion by which the moon was fractured off from the earth and assumed the dignity of an independent body. It must be remembered that the sun produces tides in the earth as well as the moon, but the solar tides are so small compared with the lunar tides, that we have hitherto been enabled to neglect them. There could however have been no lunar tides before the moon existed, and consequently in the early ages before the moon was detached the earth was disturbed by the solar tides, and by the solar tides alone.

The primæval earth thus rose and fell under the tida? action of the sun. Probably there were no oceans then on the earth; but tides do not require oceans, or even water, for their operation. The primitive tides were manifested as throbs in the actual body of the earth itself, which was then in a more or less fluid condition. Even at this moment bodily tides are disturbing the solid earth beneath our feet; but these tides are now so small as to be imperceptible when compared with the oceanic tides.

( $T$ o be continued.)

\section{SOME "GUESSES AT TRUTH" OF THE EMPEROR KHANG-HI}

K HANG-HI or Khang-hsi, one of the greatest of Chinese emperors, and indeed of Asiatic rulers, was born in 1653 and ascended the throne in 1661 . For 